\title{
MODELING HOT WATER BATH TREATMENT OF FRUIT USING LATERAL METHOD OF LINES IN SCILAB
}

\author{
Agah D. Garnadi ${ }^{1, *}$,Prasetyaning Diah R. Lestari ${ }^{2}$ \\ 1 Bogor Agricultural University;agah.garnadi@gmail.com \\ 2 The Agency for the Assessment and Application of Technology;diah.rizky@bppt.go.id \\ * Correspondence: agah.garnadi@gmail.com;Tel.: +62-251-8625-276
}

\begin{abstract}
One of essential procedure nowadays to analyze a dynamic process in Science and Engineering is Computational modeling. Most of dynamic processes are distributed parameter systems, i.e., systems with state variables depend on the number of independent variables (such as space and time) which are expressed by a set of Partial Differential Equations (PDEs). Lateral method of lines is a method which used for solving PDEs numerically by solving a set of boundary value problems sequentially. The aim is to report the development of PDE toolbox based on SCILAB. This paper provides users with a method that is very easy to understand in the applications related to dynamic process. The method uses a SCILAB template to develop numerical simulations in the new field. In this paper, a model of tropical fruit heat treatment for decimating insect is presented. The illustration will be given to show how the lateral method of line template works to solve the problem.
\end{abstract}

Keywords: Hot Water Bath Immersion; Simulation model; Lateral method of lines; SCILAB.

\section{Background}

In the tropical country like Indonesia, most of fruit farmers have to face the post-harvest problem, i.e. the attack of insect larvae pests, such as worms or fleas. The use of chemical material to overcome this problem will bring bad impact for people health. In the other hand, the use of biology agents which are the potential antagonist for insect larvae pests needs very high cost and also difficult in its application. One of the easier and cheaper alternative solutions is dipping the fruits into the high temperature water so that the insect larvae pests will be died But in practice, the longer the fruits are dipped into the hotwater, the more physical damage to the fruit that will reduce its quality. Farmers can obtain the effective immersion time for this process by trying several times of immersion and guessing how long these fruits have to have been lifted so that larvae pests can be eradicated without causing fruits damage. However, it would be saving cost and time, if there is a quick way to determine the effective immersion time without having to perform physical experiments, with the nature of the physical and thermal properties of fruit are known. Simulation using mathematical modeling is widely known as a tool which describe the behavior of a system in nature or society without testing it directly in the real world so thatit will be the solution to the problem. This paper formulates a mathematical model by solving heat equation to predict the effective immersion time in process of insect larvae pests eradication by dipping the fruits into high temperature water.

Parabolic Partial Differential Equations (PDEs), is one of differential equations which play an important role in modeling various problems arising from the diverse phenomena in the world. Some of the simple heat equation can be solved easily and have the exact solutions. However, there are also many problems modeled in the heat equation which are difficult to be solved due to its exact solution is difficult to be found or even do not have the exact solution. If the solution exist but it cannot be found by exact method, it can be solved using numerical method as an alternative. So, it 
requires routine (program) which is able to solve PDEs numerically. However, the number of software that provides a numerical routine for this purpose is as yet very slightly.

On the other hand, the routines which are able to solve Ordinary Differential Equations (ODEs) have grown a lot and already been a package in almost numerical software available today. This paper presents a tutorial of techniques for solving heat equation numerically by solving the boundary condition problem for ODEs and its application in hot water bath treatment of tropical fruit using lateral method of lines. The routine used is available in the SCILAB named bvode. The tutorial about how to use and information about bvode can be seen in [1]. There is one method to solve the evolution equation numerically, known as method of lines $([2,3])$. This method is done by doing space discretization using finite difference [3] or collocation $([2,4])$, in order to obtain an initial value problem for an ODE system. In commercial PSE MATLAB, there is pdepe routine to solve spatial 1-dimensional parabolic equation. This routine based on [4] that use collocation method for space discretization. Another approach to solve evolution PDEs is using time discretization strategy first, and then the boundary value problem for ODEs can be obtained for each time step. It means the boundary value problem for ODEs must be solved sequentially. This technique is often known as the lateral method of lines, and also known as Rothe method. In [5], there is review about the lateral method of lines. This paper is written as one of tutorial of the numerical software used to solve PDEs in general. Another purpose of this paper is to support the Indonesian Goes Open Source (IGOS) in the field of Scientific Computing, considering the SCILAB is free software. Furthermore, this paper can be the first step in the procurement of alternative software that can be used, in addition to commercial software MATLAB that is quite popular with its pdepe routine. In this paper, the heat equation will be reviewed first. Then, time discretization will be briefly shown, so the boundary condition problem form for ODEs can be obtained for each discrete time step. Thus, this form can be converted so that it can be solved by using bvode in SCILAB. After the form has been converted, then the implementation for hot water bath treatment of tropical fruit using lateral method of lines will be shown using SCILAB.

\section{Methods}

In this paper, a model of tropical fruit heat treatment for decimating insect is presented. This illustration gives the knowledge about hot water bath treatment for fruit to kill insect larvae pests using lateral method of line and how to solve it using SCILAB.

Heat conduction process on a known medium physically affected by heat diffusivity coefficient that is a value which states the ability of medium to conduct heat. The medium can be assumed as a rod, thus the differential equation model of heat conduction problem can be easily obtained. With this assumption, there are only two independent variables, $t$ and $x$, where $t$ is time and $x$ is length (in space) between each node on a rod. If $\theta(t, x)$ is a function that states the medium temperature at time $t$ and at position $x$, then the heat conduction can be expressed in the form:

$$
\frac{\partial \theta}{\partial t}=\nabla \alpha \nabla \theta
$$

Heating condition at the beginning of the observation, at $t=0$, can be expressed in the form of initial value problem below:

$$
\theta(0, x)=\theta_{0}(x) \quad \ldots(2)
$$

The fruit that will be dipped can be assumed as a sphere with a radius $R$ and a constant diffusivity coefficient $\alpha$. The equation (1) will be reformed into:

where $r$ is the spherical coordinate variable for dipped fruit.

$$
\frac{\partial \theta}{\partial t}=\alpha \frac{1}{r^{2}} \frac{\partial}{\partial r} r^{2} \frac{\partial \theta}{\partial r}
$$

To declare that there is no change in the rate of temperature in the center of sphere, at $r=0$, and that the fruit's temperatures while dipping is $T$, consider the following two boundary conditions: 


$$
\begin{aligned}
& \left.\frac{\partial \theta}{\partial r}\right|_{r=0}=0 \quad \ldots(4) \\
& \theta(t, R)=T \quad \ldots(5)
\end{aligned}
$$

Although the PDEs (3) has the analytic solutions, but the form itself cannot be reformed into basic elementary function. In this case, the numerical solutions are needed. Because of equation (3) is PDE so the discretization process is needed to obtain ODE that can be solved using numerical method. In this paper, the Rothe method is used, or commonly known as lateral method of line [6] that is discretization to time $t$ that done first so that for every time step the boundary value problems for ODEs can be obtained as follows:

$$
\begin{array}{r}
\frac{1}{\alpha} \frac{\theta^{k+1}(r)-\theta^{k}(r)}{\Delta t}=\frac{2}{r} \frac{d \theta^{k+1}(r)}{d r}+\frac{d^{2} \theta^{k+1}(r)}{d r^{2}} \ldots \text { (6) } \\
\frac{d \theta}{d r}(0)=0 \quad \ldots \text { (7) } \\
\theta^{k+1}(R)=T \quad \ldots \text { (8) }
\end{array}
$$

By considering equations (6), (7) and (8), the solutions of ODEs can be solved numerically. In free software SCILAB, there is a routine to solve the boundary value problems so that Rothe method can be easily implemented.

\section{Results}

This section will discuss about a case study on hot water bath treatment of tropical fruit that has been solved using SCILAB. The simulation is applied to a case of Indonesian local apple variety, known as Apel Malang, which is developed using two treatments, each treatment using different immersion temperatures.

\subsection{Test data for Indonesian local Apple and fruit flies tolerances of heat}

\section{- Apel Malang (Malus Sylvestris Mill)}

Indonesian localapple variety called Apel Malang is used in this experiment that assumed as a perfect sphere. It can be assumed the initial temperature for Apel Malang is $29^{\circ} \mathrm{C}$. The experiment done using two treatments, the first medium (hot water) temperature is $47^{\circ} \mathrm{C}$ and the second one is $60^{\circ} \mathrm{C}$, note that this dipping medium temperature is homogenous and kept at stable over time. With water content of fruit $83 \%$ then obtained the value of heat conductivity and heat diffusivity, 0.005979 Watt $/ \mathrm{cm}^{\circ} \mathrm{C}$ and $2.0990 \times 10^{-3} \mathrm{~cm}^{2} /$ second, respectively. [7]

- Fruit Flies (RhagoletisPomonella)

According to Fields [8], lethal temperature for insects is in the specific range that can be seen in the following table.

Table 1. The lethal temperature of stored-product insect pests[8]

\begin{tabular}{|c|c|}
\hline $\begin{array}{c}\text { Range of lethal } \\
\text { temperature }\left({ }^{\circ} \mathrm{C}\right)\end{array}$ & Effects \\
\hline$>62$ & Died less than a minute \\
\hline $50-62$ & Died less than an hour \\
\hline $45-50$ & Died less than a day \\
\hline $35-45$ & $\begin{array}{r}\text { Populations die out, mobile insects } \\
\text { seek cooler environment. }\end{array}$ \\
\hline
\end{tabular}


This paper assumes fruit flies larvae live in areas which are not deeper than $0.5 \mathrm{~cm}$ from the fruit skin. Based on data from Table 1, the immersion of fruit can be simulated using numerical method. By using SCILAB, the numerical solution of heat equations problem above can be used to predict the effective immersion time.

The following are results of simulation using two treatments, each treatment using a different immersion temperature.

\subsection{Simulation results}

First case. By taking the hot water bath temperature at $47^{\circ} \mathrm{C}$, the heat distribution curve can be seen as follows:

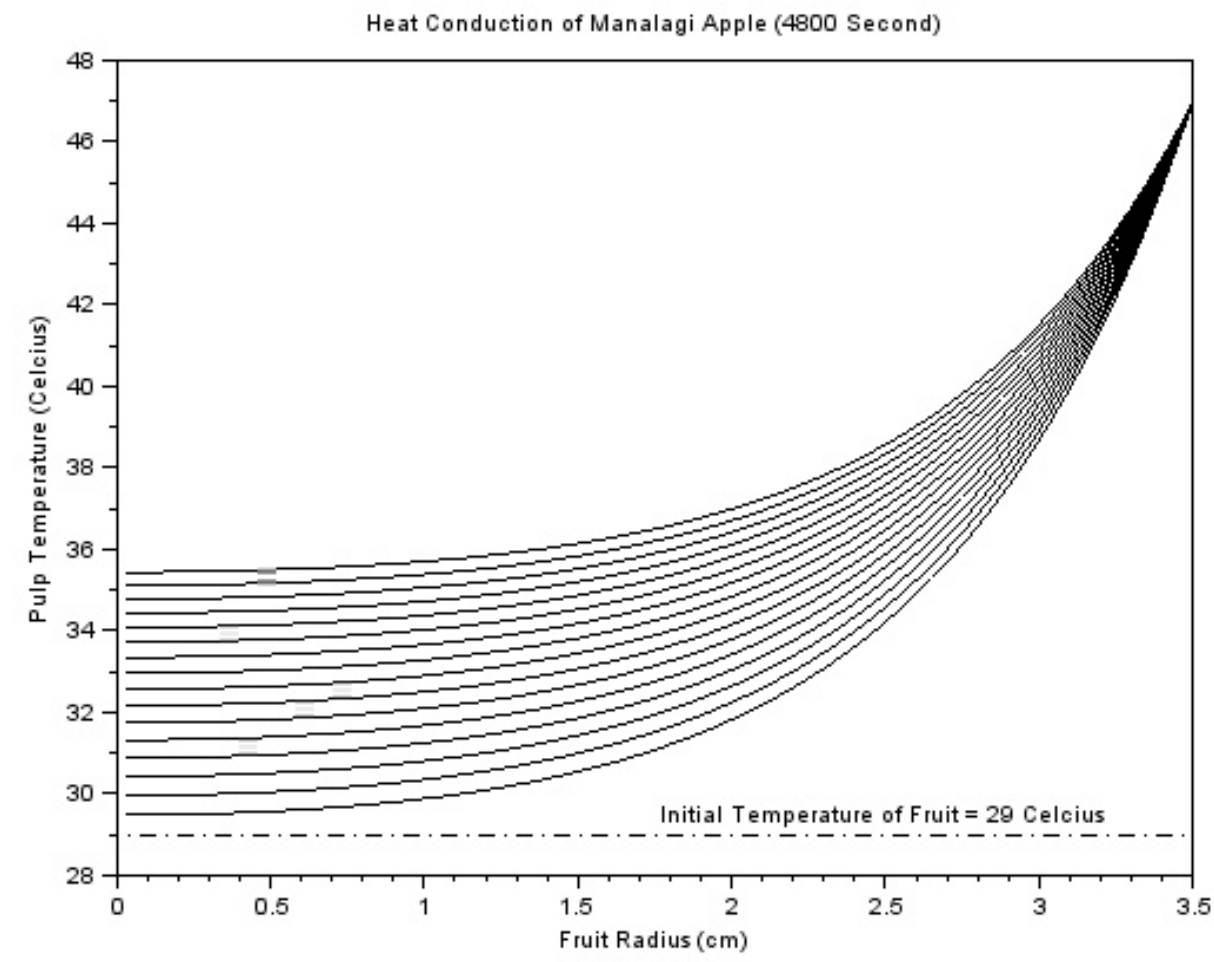

Figure 1. Simulation using hot water bath temperature $47^{\circ} \mathrm{C}$

Simulation is done successfully by taking step for every 5 minutes, for 80 minutes. Consider the initial temperature of Apel Malang is equal to room temperature $\left(29^{\circ} \mathrm{C}\right)$.

Second case. By taking the hot water bath temperature at $60^{\circ} \mathrm{C}$, the heat distribution curve can be seen as follows: 


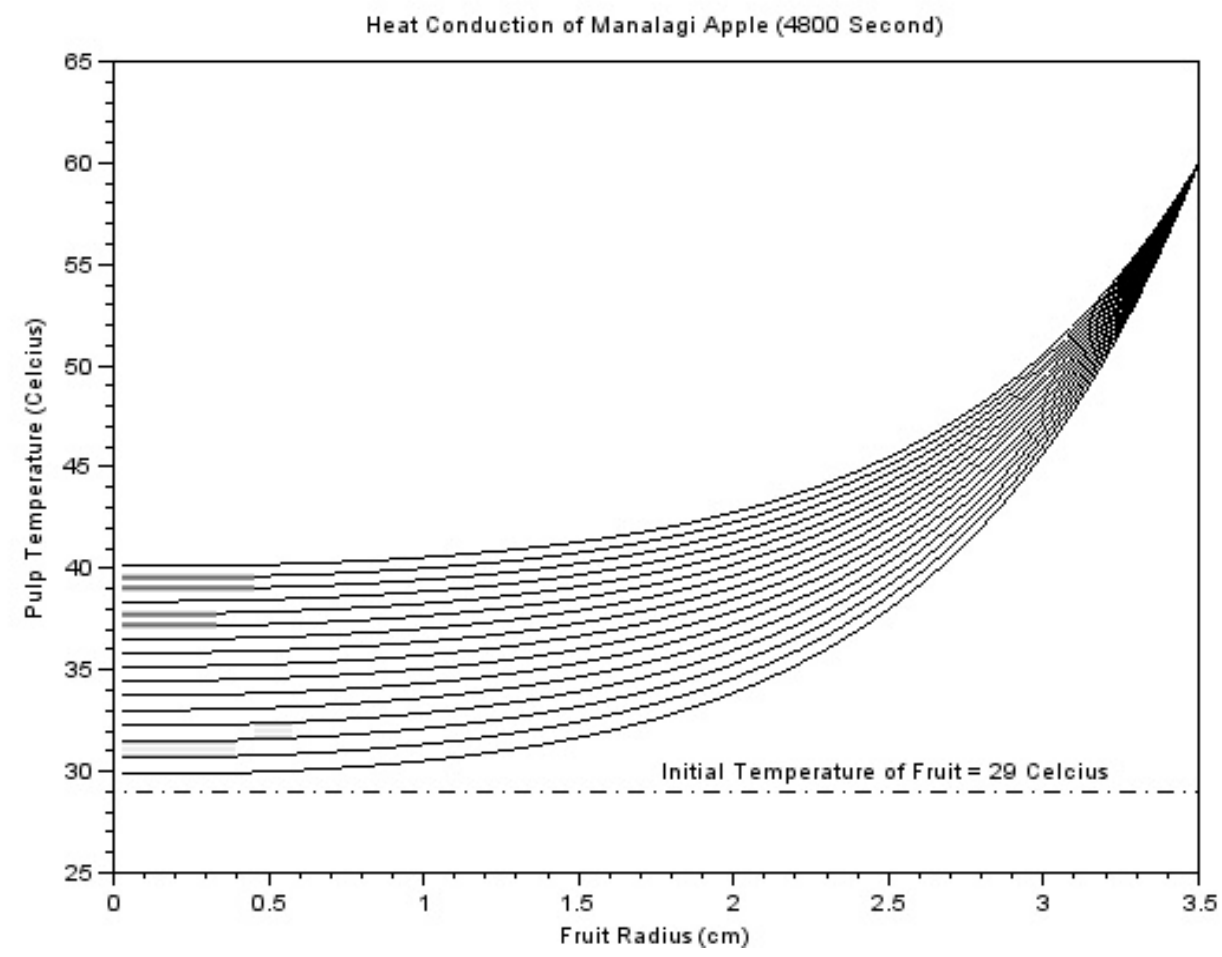

Figure 2Simulation using hot water bath temperature $60^{\circ} \mathrm{C}$

Similar to the first case, this simulation is also done successfully by taking step for every 5 minutes, for 80 minutes, and the initial temperature of Apel Malang is also equal to the room temperature $\left(29^{\circ} \mathrm{C}\right)$.

\section{Discussion}

For the first case, at the end of simulation known that the temperature at a depth of $0.5 \mathrm{~cm}$ from the fruit skin reaches about $41.5^{\circ} \mathrm{C}$. According to Table 1, it means that the immersion process for this case fails to kill fruit flies larvae which live in that depth. The longer the immersion time, the fruit can be physically damaged. It means that the only possible treatment is by increase the medium temperature of hot water. For the second case, at the end of simulation known that the temperature at a depth of $0.5 \mathrm{~cm}$ from the fruit skin reaches about $51^{\circ} \mathrm{C}$. Based on Table 1, this immersion process success to kill fruit flies larvae which live in that depth due to heat penetration happened during the immersion. By considering these two case studies, we conclude that the fruit immersion process into a medium (water) with high temperature can be carried out to kill insects that live in the fruit pulp. However, the heat penetration that occurs due to this process can cause physical damage to the fruit which will ultimately reduce the quality of the fruit. As a result, the temperature and immersion time should be taken such that the insects live in the fruit pulp can be killed without damage the fruit. In summary, simulation using heat equations model can be used to obtain combination between medium temperature and immersion time so that the immersion process gives an optimal result.

\section{Conclusions}

This paper shows that how mathematical modeling and simulations can be incorporated in the post-harvest problem. An appropriate mathematical model for the problem (i.e. PDEs) can capture the heating phenomenonof hot water bath treatment for fruit to kill insect larvae pests. In this work, it has been demonstrated an implementation of solving PDEs numerically with one spatial dimension in SCILAB using a sequence of boundary value problem ODEs solver to solve the post-harvest problem for fruit farmers. 
The simulation results based on 2 case studies show that the fruit immersion process in the medium (water) with high temperature can be carried out to kill insects that live in the fruit pulp. The goals of saving cost and time to do the immersion process has been achieved through the implementation of solving PDEs numerically.

Future work opportunities would be the development of lateral method of line implementation in other phenomena and systems in our nature or society within SCILAB numerical libraries. This development is directed towards a tool that on par to that pdepe library in Matlab, following on the rule of Schryer[9].

Author Contributions: The following statements should be used "conceptualization, A.D.G.; methodology, A.D.G.; software, A.D.G. and P.D.R.L.; validation, A.D.G and P.D.L.; formal analysis, A.D.G; investigation, A.D.G. and P.D.L.; resources, P.D.R.L.; data curation, P.D.R.L.; writing-original draft preparation, A.D.G.; writing - review and editing, A.D.G. and P.D.R.L; visualization, P.D.R.L.; supervision, A.D.G.".

Funding: Please add: "This research received no external funding"

Acknowledgments: In this section you can acknowledge any support given which is not covered by the author contribution or funding sections. This may include administrative and technical support, or donations in kind (e.g., materials used for experiments).

Conflicts of Interest: “The authors declare no conflict of interest."

\section{Appendix A}

SCILAB script of hot water immersion for insect disinfestations.

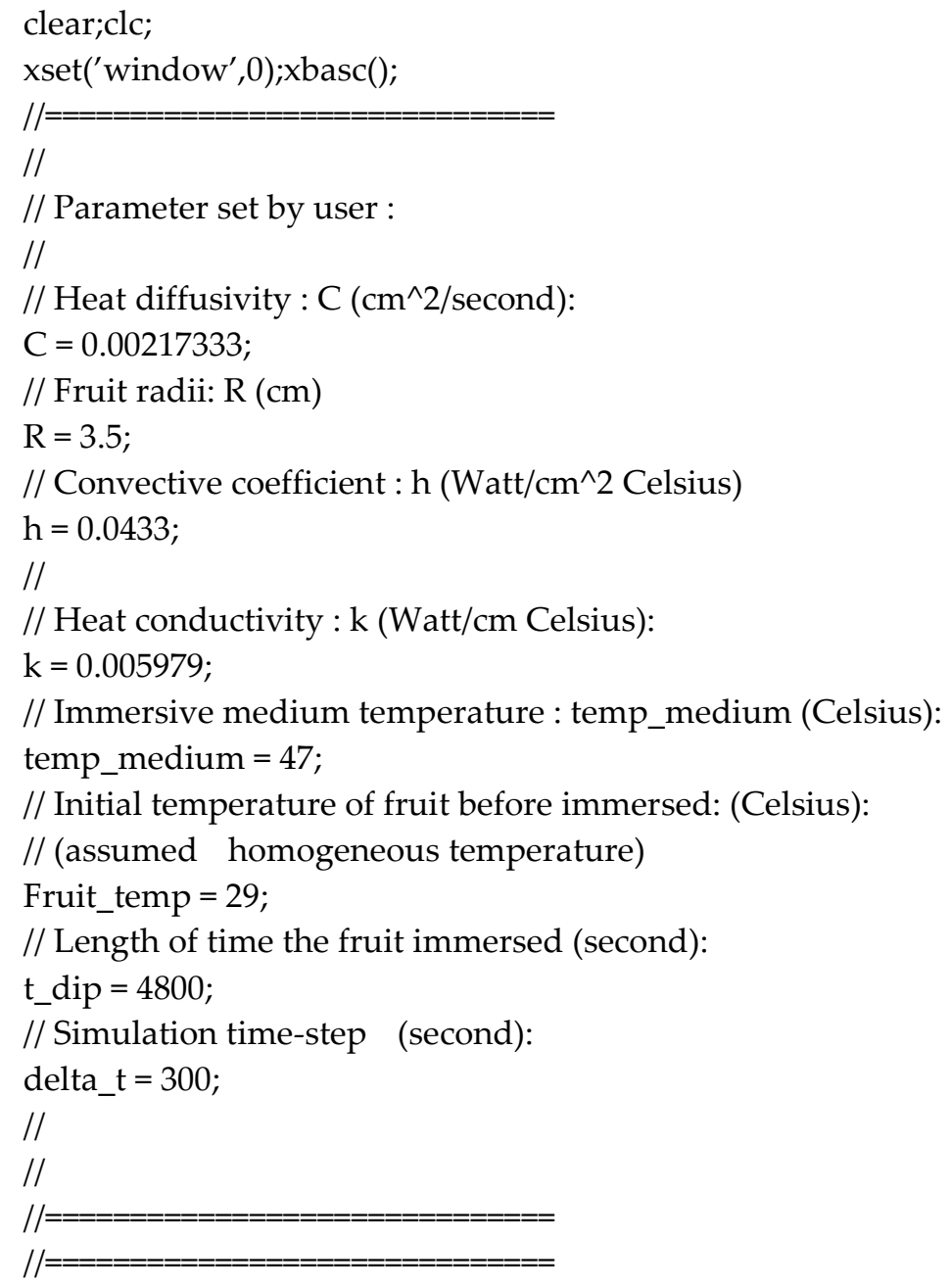




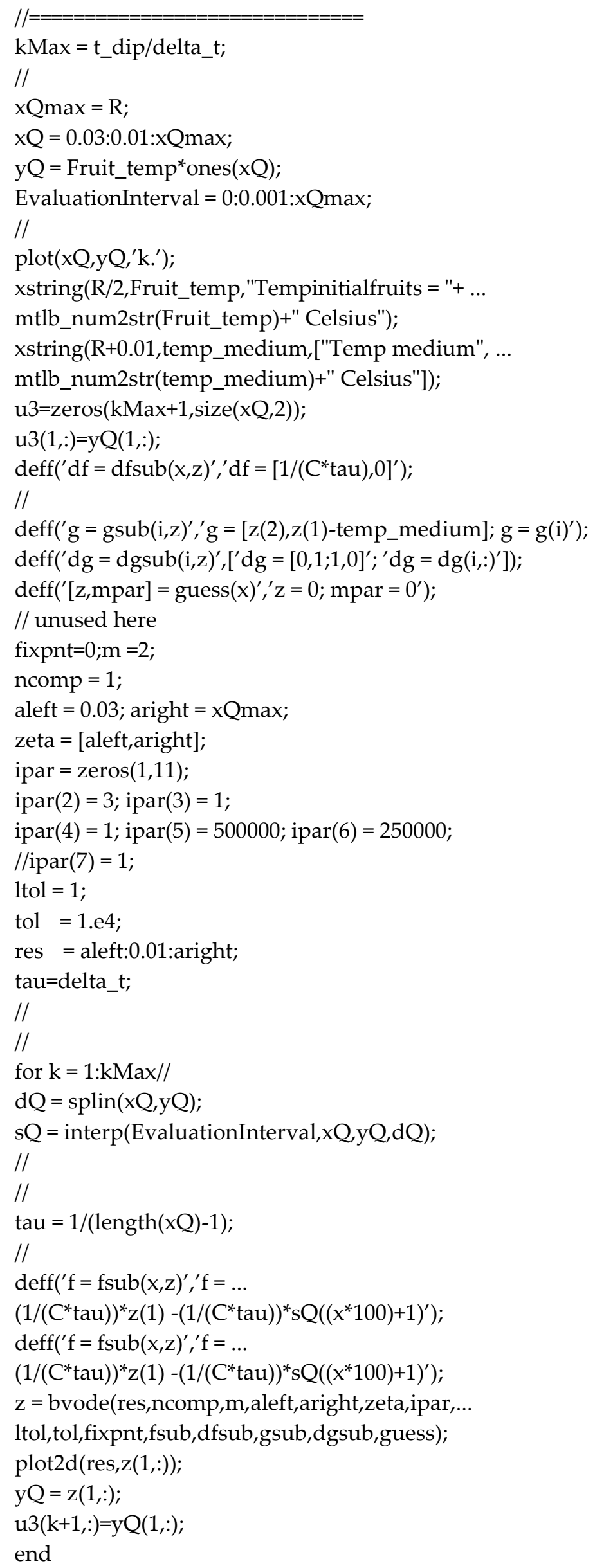


xtitle("Heat Conductive ...

ApelManalagi ...

("+mtlb_num2str(t_dip)+" second)", ...

"Radius fruits (cm)","TempFruits Pulp (Celsius)");

//xtitle(mtlb_num2str(t_dip)+" second");

//xset('window',1);xbasc();plot3d([0:kMax],xQ,u3);xselect();

//xtitle("Heat Conductive ApelManalagi","t","r","T");

//fplot3d([0:1:20],[-10:1:10], green,45,45,"X1@X2@X3");

printf("\ndone $\backslash \mathrm{n} ")$

/I 


\section{References}

1. Ekastrya, D., Ayatullah, F.; Garnadi, A.D.; Menyelesaikan Persamaan Differensial Biasa - Syarat Batas dalam SCILAB menggunakan bvode, JMA v7n1, 1-10, 2006.

2. Madsen, N.K.; Sincovec R.F.; ALGORITHM 540: PDECOL, General Collocation Software for Partial Differential Equations, ACM TOMS, 1979, vol. 5, No.3, 326-327.

3. May, R.L., Numerical Solution of PDE's using The Methods of Lines, TR No. 2, Dept. Math., RMIT, 1990.

4. Skeel, R.D.; Berzins, M. A.; Method for the Spatial Discretization of Parabolic Equations in One Space Variable, SIAM J. Sci.Stat.Comp., year, v11, 1-32.

5. Garnadi, A.D.; Masalah Syarat Batas Bebas Persamaan Diferensial Parsial Parabolik Satu Dimensi. JMA, v3n2, 11-28, 2004.

6. Ascher, U.; Christiansen, J.; Russel, R.D.; Collocation Software for Boundary Value ODEs, ACM ToMS, 1981, vol 7(2), 209-222.

7. Fahmi, A.; Kajian Penetrasi panas pada buah apel (Malus Sylvestris Mill) selama proses heat treatment, Tesis (Pascasarjana)-InstitutPertanian Bogor, 2004.

8. Fields, P.G.; Alternatives to Methyl Bromide Treatments for Stored-Product and Quarantine Insects. Annu. Rev. Entomol, 47:331-59, Cereal Research Centre, Agriculture and Agri-Food Canada, 2002.

9. Schryer, N.L., Designing Software for One-Dimensional Partial Differential Equations, ACM Transactions on Mathematical Software. vol. 16, No.1, 72-85, 1990.

10. Ascher, U.; Mattheij, R. M.; Russel, R.D.; Numerical Solution of Boundary Value Problem, Prentice-Hall: New Jersey, USA, 1988

11. Campbell, S.L.; Chancelier, J.P.; Nikoukhah, R.; Modeling and Simulation in SCILAB/Scicos, Springer:Berlin, Germany, 2005.

12. Poulikakos, D., Conduction Heat Transfer, New Jersey: Prentice-Hall International. 1994.

13. Hariyadi, P., Sitanggang, A.B., dan Purnomo, E.H.,2019, PindahPanasTakTunak dan PenukarPanas, dalam P. Hariyadi (editor), Landasan Teknik Pangan,(pages 205-256) Penerbit IPB Press

14. Wirakartakusumah, M.A.; Abdullah, K.; Syarif, A. M.; Sifat FisikPangan. Departemen pendidikan dan Kebudayaan, Direktorat Jenderal Pendidikan Tinggi Pusat antar Universitas Pangan dan Gizi, Bogor: Institut Pertanian Bogor. 1992. 